\title{
An Evaluation of Digital Portfolios in Coach Education: Developing Reflective Coach Practitioners
}

\author{
Michelle L. Albaugh \\ Illinois, USA
}

\author{
Kimberly S. Scott \\ Illinois, USA
}

\author{
Amy L. Conn \\ Illinois, USA
}

\begin{abstract}
Although portfolios have not yet gained widespread use in the field of coach education, they hold considerable promise for the development of reflective coach practitioners. However, it is unclear under which conditions their use is most successful. The purpose of this article is to examine the use of digital portfolios in graduate coach education and to offer recommendations for the adoption of portfolios in developing reflective practice among students. Data from 28 qualitative interviews eliciting student reactions to digital portfolio assignments were content analyzed in a summative assessment of reflection and learning. Illustrative examples are presented. Key advantages identified include student reflection and synthesis of material across multiple courses, development of professional identity, unique learning and value derived from writing for an anticipated audience, and unanticipated personal and professional benefits that extended beyond the bounds of the classroom. The article concludes with implications for including digital portfolios in coaching curricula and developing reflective coach practitioners.
\end{abstract}

Keywords: reflection, reflective practitioner, coach education, digital portfolio, ePortfolio

\section{Introduction}

As with many other professions that require skilled practitioners to work with their subjects in highly interpersonal engagements (e.g., doctors and nurses with patients; teachers with students; consultants and lawyers with clients), coaching requires a commitment to ongoing development and reflection to achieve peak performance. Reflection is regularly mentioned among the 
fundamental practices that coaches use with their clients, but - with a few exceptions - less often when it comes to educating, training, and developing coaches (Bachkirova, 2016; Cavanagh, 2006; Cavanagh \& Spence, 2013; Kemp, 2008; McLean, 2012). Perhaps it goes without saying that coaches need to be reflective practitioners. And perhaps it is implied within lists of coaching competencies that active, critical reflective practice should be one hallmark of an effective and experienced $\operatorname{coach}^{1}$.

Learning and reflection are essential elements of coaching - if not inherent in its definition (Cox, 2006; Cox, Bachkirova, \& Clutterbuck, 2014; Flaherty, 2011). Reflection also is credited for its important role in helping coaches develop their ethical capabilities through critical self-evaluation of their values, assumptions, beliefs, and actions within the context of their political, social, and cultural backgrounds (Bachkirova, 2016; Iordanou \& Williams, 2017). However, to be a reflective practitioner requires more than simply being thoughtful about your work. It requires both elevating and interweaving reflective practice (awareness, inquiry, discovery, meaning making) during and after client-facing work (Schön, 1983). This requires consistent skill-building and intentional, ongoing practice with reflective thinking.

Reflective practice typically is developed through writing exercises such as journaling or maintaining a diary, or, more commonly in the field of coaching, in writing notes or in conversation with a supervisor (Bachkirova, 2016; Hawkins, 2009). In teacher education, portfolios have been used for decades as a tool to facilitate both reflective practice and assessment (Butler, 2006). One valuable byproduct of portfolio use has been the encouragement of learners in this context to take more responsibility for their own learning (Butler, 2006). Although portfolios have not yet gained widespread use in the field of coach education, they hold considerable promise for the development of reflective coach practitioners. Furthermore, with the digital economy transforming the nature of business interactions and employment relationships (Anderson \& Wladawsky-Berger, 2016), digital portfolios in particular offer

\footnotetext{
${ }^{1}$ For sample competencies, see for example websites from these coach credentialing organizations: International Association of Coaching (https://certifiedcoach.org/certificationand-development/the-coaching-masteries/), Center for Credentialing and Education (http://www.cce-global.org/Credentialing/BCC), Worldwide Association of Business Coaches (https://www.wabccoaches.com/includes/popups/competencies.html), Society for Industrial and Organizational Psychology (Vandaveer, Lowman, Pearlman, \& Brannick, 2016), and the International Coach Federation (https://www.coachfederation.org/credential/).
} 
opportunities for coach education to develop reflective practitioners who can thrive in the dynamic, customer-focused, collaborative, innovation-driven environments in which many of their clients now work and live.

\section{Reflection and reflective practice}

Reflection is foundational to how coaches work with clients but is less often the focus for their own growth and development (Cavanagh, 2006; Cavanagh \& Spence, 2013; Kemp, 2008; McLean, 2012). Reflection is a rigorous meaning-making process that serves as a tool to integrate and transform knowledge and experience (Rodgers, 2002a). In this way, it exhibits certain parallels with coaching processes. Reflection is an "iterative, forwardmoving spiral from practice to theory and theory to practice" (p. 863). Schön (1983) suggests this sort of rigorous, individual reflective experimentation is vital to develop a form of professional practice that remains effective in an increasingly VUCA (volatile, uncertain, complex, and ambiguous) world, where no standard, technical solutions exist. In The Reflective Practitioner, Schön (1983) describes 2 types of reflection: (1) reflection-on-action, which takes place after the fact and informs how practice can be developed or changed after the event; and (2) reflection-in-action, which takes place in the moment and informs how shifts in practice can yet influence the event.

Schön (1983) argues that, through reflection, practitioners "can surface and criticize the tacit understandings that have grown up around the repetitive experiences of a specialized practice, and can make new sense of the situations of uncertainty or uniqueness which he may allow himself to experience" ( $p$. 61). As students of coaching allow themselves to experience the surprise and discomfort of learning and implementing new theories and methods of coaching, this sort of reflective practice is useful to integrate current learning and build increasing capacity to challenge assumptions and apply previous learning to novel or ill-formed challenges for themselves and their future clients. Next, we discuss how digital portfolios might play a role in developing reflective practice.

\section{Digital portfolios}

A digital portfolio, sometimes referred to as an ePortfolio, is a collection of evidence to show what a person has learned over time and to demonstrate their abilities (Barrett, 2007; Butler, 2006). Although digital portfolios are a pragmatic mechanism for storing visual and auditory content (Abrami \& 
Barrett, 2005), they are also meant to be "generative, reflective and indicative of one's technological competencies" (Hicks et al., 2007, p. 457).

\section{Why use digital portfolios}

In recent decades, the use of portfolios has become widespread in higher education (Clark \& Eynon, 2009). They appeal to educators in part because they can be used to facilitate assessment (e.g., documenting attainment of a standard), scaffold deep learning, and demonstrate professional competence (Barrett, 2005, 2007; Orland-Barak, 2005). For example, digital portfolios can quickly give a potential employer a broad view of both achievements and thinking, thereby providing an immediate 'whole person view' of potential candidates (Burksaitiene, Tereseviciene, \& Kaminskiene, 2011). As such, they can become learning artifacts for students that have value beyond the completion of a class assignment.

The "digital" aspect of digital portfolios cannot be overstated. First, digital portfolios may help students develop the competencies and confidence necessary to engage in technology-assisted coaching. Second, they can facilitate learning and development using technology-based coaching tools. Third, educators are increasingly urged to prepare students for the digital environments in which they will live and work (21st Century Learning Reference Group, 2014; Arquero \& Romero-Frías, 2013; Greenhow, Robelia, \& Hughes, 2009; McLoughlin \& Lee, 2010; U.S. Department of Education Office of Educational Technology, 2010). The field of coaching is not immune from these changes in our society, and they directly impact how coaches interact with their clients. Some reports estimate that technology-assisted coaching now accounts for $50-60 \%$ of coaching delivered (Kanatouri \& Geibler, 2017). There are many technology-assisted options available for engaging in coaching, including via telephone, webcam, email, video, text and mobile app. Not only must coaches be adept at using the communication and collaboration technologies preferred by their clients, they also should be capable of contributing to online communities of practice in coaching. As such, the fourth reason why digital portfolios are important is that they ideally teach coaches how to use the digital portfolio platform to become skilled at adding their authentic voices to technology-mediated discussions about the practice of coaching, in service of nurturing, guiding, and maturing this emerging field of professional coaching. 


\section{How digital portfolios facilitate learning}

From a learning and design perspective, learning portfolios traditionally included five steps: Collecting, Selecting, Reflecting, Projecting, and Celebrating (Barrett \& Wilkerson, 2004). Technology affords at least five additional opportunities: "Archiving, Linking/Thinking, Storytelling, Planning, Publishing" (Barrett \& Wilkerson, 2004). When used in a formal education program ${ }^{2}$ these steps can unfold over short or long durations and be used for one class or to support learning across an entire program's curriculum. For example, in a single coach training class, the instructor can set up a portfolio structure that encompasses topics mapped to individual course learning objectives. Students can use their portfolios to build digital artifacts that are refined throughout the course. For example, when educating coaches, these digital artifacts might include a list of coaching resources, an executive summary of an academic article, a book critique, critical reflection about a coaching framework, or a case study of a challenging client engagement.

Students collect and curate the content to include in their portfolios, and then they reflect on the content they created. The final portfolio may be the object of a reflection paper; alternatively, students can submit reflections about each artifact as it is being constructed. Digital portfolios can be easily shared with classmates, and on some technology platforms they can be made publicly available. As a culminating project of a class or program, the successful completion of digital portfolios can be celebrated and promoted as one indication of proficiency.

Reflection is a fundamental learning skill that is considered to be an essential process underlying the effective construction of digital portfolios (Scott, 2010; Yancey, 2009). Digital portfolios not only provide a holding place for reflective writing, but they also enhance reflection and self-regulation by making it easy for students to return to their selected artifacts and modify their thoughts or goals (Abrami \& Barrett, 2005; Scott, 2010). Portfolios also support self-directed learning skills, including goal-setting, task-analysis, plan implementation, and self-evaluation (Beckers, Dolmans, \& van Merrienboer, 2016; Scott, 2010). However, it is unclear under which conditions their use is most successful or whether there are individual differences that impact their utility. For example, Cheng and Chau (2013) found a connection between goal

\footnotetext{
2 The authors' comments here integrate their experience using digital portfolios in a graduatelevel coaching certificate program.
} 
orientation and digital portfolio development, suggesting that students with a blend of mastery and performance orientations are more persistent and reflective in their work than students with a single goal orientation.

Furthermore, one investigation into the quality of reflective content in educator portfolios found a predominance of technical or descriptive reflection rather than the sort of critical reflection required to be a reflective practitioner (Orland-Barak, 2005). This research suggests that there is potential for portfolios to support the development of reflective practitioners, but the desired learning outcomes may not be achieved simply by requiring their use.

\section{Theoretical frameworks underlying digital portfolios}

The emphasis on self-directed learning and reflection processes during digital portfolio construction leads us to consider the theoretical grounding for their application to coach education. Constructivist learning theory and social constructivism provide underlying principles upon which digital portfolio implementations may be built.

\section{Constructivist learning theory}

From a constructivist perspective, learning is an active process that requires learners to engage in sense making to organize and construct their knowledge (Bransford, Brown, \& Cocking, 1999; Mayer, 2004). Students construct their knowledge by reflecting and building upon their current experiences and prior knowledge, rather than knowledge being acquired through "traditional" mechanisms of observation, repetition and memorization. Social constructivism further elevates the importance of collaboration within a social context to build knowledge. It is centered around the idea that our sense of self and our social realities are created through verbal and nonverbal interactions with others, as well as how we make sense of those interactions (Cunliffe, 2004).

Facilitating the construction of knowledge requires creating learning environments where students can experience authentic and meaningful tasks that allow them to engage in thoughtful reflection on their experiences and make connections to new content (Jonassen, 1999; Land, Hannafin, \& Oliver, 2012). This begins by establishing a problem, question, or project that is the focus of the learning experience and constitutes the learning goal for students (Jonassen, 1999). When using digital portfolios, the purpose and audience for the portfolio are established first, along with question prompts or guidelines for portfolio content based on the learning objectives. Resources, tools, scaffolding, 
and support systems, including communities of learners and coaches/facilitators, are provided to help students complete the project, with the underlying premise that students learn the content to complete the project rather than completing the project to apply what was learned (Barab \& Duffy, 2012; Jonassen, 1999). Providing students with opportunities to collaborate, share their digital portfolios, and exchange feedback expands the potential for reflection and meaningful learning.

The coaching and facilitation provided in these learning environments is intended to motivate learners, monitor their progress, offer feedback and advice, and encourage reflection about what is being learned by asking provoking questions (Hmelo-Silver \& Barrows, 2008; Jonassen, 1999). Reflection in this context follows Dewey's definition of reflective thinking, which emphasizes the systematic, rigorous and disciplined process of meaning making from experience (Rodgers, 2002a). This type of reflection, most effective when it happens with others, follows a cycle of being present during the experience, describing the experience without interpretation, analyzing the experience from multiple perspectives, and then experimenting with new actions in the next experience (Rodgers, 2002b).

Following from these principles are several student-centered teaching methods, such as problem-based learning and collaborative learning, which give students an active role in making decisions about and pursuing their learning, with the goal of facilitating more meaningful, deep levels of learning (Land et al., 2012). Reviews of the literature suggest that student-centered learning environments are complex, with both student characteristics (e.g., personality, age, motivation, self-confidence, self-efficacy) and contextual factors (e.g., appropriateness of the workload, information, teacher quality, clarity of goals and standards, etc.) affecting the depth of learning achieved (Baeten, Kyndt, Struyven, \& Dochy, 2010). As a learning tool typically embedded in a student-centered environment, digital portfolios are subject to many of these same factors that may encourage or discourage more meaningful levels of learning. The purpose of this study, then, was to examine the use of digital portfolios in graduate coach education and to offer recommendations for the adoption of portfolios in developing reflective practice among students. The questions that guided the evaluation included the following: (1) Did the digital portfolio assignments successfully facilitate student reflection and learning? (2) What can student accounts of their experience with the digital portfolio assignments tell us about the conditions under which their use is most successful? 


\section{Method}

\section{Program background: Digital portfolios in the context of a graduate-level coach education program}

The coach education and training program examined in this study is situated within the Northwestern University Master of Science in Learning and Organizational Change (MSLOC) program, which offers a graduate-level Organizational and Leadership Coaching Certification (OLCC) ${ }^{3}$. The MSLOC program offers both traditional evening format courses and hybrid learning courses that combine both face-to-face and technology-mediated instruction. The OLCC program participants are distributed across the United States, but it is not an "online program." Participants meet in person for some of the classes during the year-long program. One distinguishing feature of MSLOC is its commitment to building digital literacy, the knowledge and skills that help students become competent learners, participants, and contributors to digitallyenabled environments. The hybrid learning environment and program resources available to foster digital literacy provide a supportive context for the use of digital portfolios.

The OLCC program educates both experienced and new coaches. On average, students have 14 years of work experience when they apply to the program. Students begin OLCC with a self-assessment. Students use the information from the self-assessment to create individual learning plans that help them identify and focus on specific needs for their development as a coach. At the same time, all participants begin work on their digital portfolios. The digital portfolio platform and structure are provided by the program. Completed portfolios are required to contain five sections: 1) a brief personal introduction that highlights what makes the coach unique, 2) an autobiographical account of the coach's professional background and a corresponding narrative that answers "who I am," 3) a summary of the coaching resources and tools that the student selects to demonstrate her/his knowledge and approach to coaching, 4) a coaching philosophy or mission statement, which should provide an authentic point of view about coaching, and 5) testimonials or summaries of feedback the coach receives from clients coached during the program. Students share

\footnotetext{
${ }^{3}$ The first author is a full-time faculty member in MSLOC and oversees the OLCC Program; the second author is the MSLOC Program Director; and the third is a current graduate student who was a graduate assistant and not involved in the coaching certification at the time these data were collected.
} 
reflections about their portfolio contents and receive both instructor and peer feedback throughout the year.

Digital portfolios serve three purposes within the OLCC program. First, they provide scaffolding for self-directed learning and reflection throughout the duration of the one-year program, as a co-curricular addition to standard coursework. Each section of the portfolio requires students to review course content and then select and summarize how they might use that content in their coaching practice. Because the eventual target audience for the portfolios are potential clients, students need to engage in meaning making to integrate what they have learned and write about it using conversational, jargon-free language. Second, portfolios allow for an assessment of student learning. A coaching supervisor grades the final portfolio using a rubric that aligns with the program's learning objectives. Portfolios are graded for: 1) the depth of thought about the coaching models, frameworks and tools introduced in the program, 2) critical thinking about course content, 3) appropriate application of content to coaching scenarios, and 4) coherence, accuracy and clarity of writing. Third, the final portfolios may be made publicly available for students to showcase their work to prospective clients. Students can leverage part or all of their portfolios to construct websites or publish their work.

The OLCC program began using digital portfolios in 2015. The assignments and structure of the portfolios have been adjusted over time in response to instructor and student feedback. Two technology platforms also have been tested, Pathbrite and Wordpress. Following the second full year of using digital portfolios, the program initiated a study to investigate their usefulness in coach development. Forty-seven students from two OLCC cohorts were invited to participate in this research, described below.

\section{Sample \& Procedures}

The full sample included 34 alumni ( $72 \%$ of alumni from the 2 most recent cohorts) of the graduate certificate program in Organizational and Leadership Coaching (OLCC), situated within Northwestern University's Master's program in Learning and Organizational Change (MSLOC). Participants completed an assortment of quantitative surveys. At the end of the survey, participants were asked if they would be willing to be interviewed more extensively about their experiences creating digital portfolio assignments while in the coaching certificate program. Twenty-eight $(N=28)$ of these alumni agreed to be interviewed, and they constitute the sample used in the present study. Study participants were given the choice of a \$10 Amazon or Starbucks 
gift card for completing the quantitative portion of the study and an additional $\$ 10$ gift card after completing the interview.

All interviews were conducted by the third author, either face-to-face (recorded using an iPhone voice recording app) or using the Bluejeans videoconferencing platform (which has built-in recording capability), and were then professionally transcribed. The transcripts from these interviews were uploaded into NVivo 11 for Windows and coded inductively using this software, using a directed content analysis approach (Hsieh \& Shannon, 2005).

The interviews were roughly one hour and included several topic areas as they related to the digital portfolio assignments in OLCC: Overall experience, critical/evaluative comments, narrative questions, and concluding questions. The four questions from the critical/evaluative area were examined for the current study. Appendix A lists the four specific questions used.

The mean age of the interview sample was 39 (Range: 27-59), and the mean years' work experience before applying to the program was 14 (Range: 535). Thirteen participants indicated they had no coaching experience before beginning the certificate program, and 15 participants indicated they had served in a part-time, internal or informal coaching role within their organization. None of the participants who consented to be interviewed indicated they held a formal coaching role for their job.

The purpose of this study is to examine the use of digital portfolios in graduate coach education and to offer recommendations for the adoption of portfolios in developing reflective practice among students. Schön's (1983) Reflective Practitioner model informed the content analysis and helped cast a wide net to understand reflective practice in developing coaches. The specific content sought in the analyses included the full range of reflective practice identified by Schön (1983): awareness, inquiry, discovery, and meaning making.

In addition to using the digital portfolio assignments to engage in reflective practice, students were also encouraged to anticipate using the material at some point for marketing and personal brand development, as well as to develop digital literacy. Evidence of the relevance of these purposes emerged in student interviews and is also reported below. 


\section{Findings}

Table 1 displays the total number of participants who used reflective language in their interview responses (see Appendix A for question wording). Twenty-two study participants (nearly $80 \%$ ) reported a positive shift, advancement, or improvement in their thinking that was reflective in nature. Fourteen described an aspect of coach identity development, and 13 reflected on the effect of writing their reflective exercises with a current or future audience in mind. Separate from reflection, 18 participants focused on the digital portfolio as a tool to create marketing materials. Three focused on improvements in their digital skills, and four said the assignments did not add significant value to their learning or professional development. The remainder of this section illustrates student thinking and experiences behind these frequencies, through verbatim quotes that are at once representative of overall responses in a particular category and especially easy to grasp.

Table 1: Number of study participants coded for each theme

\begin{tabular}{lc}
\hline \hline Theme & Count (\%) \\
\hline Overall reflection & $22(79 \%)$ \\
Reflection and identity & $14(50 \%)$ \\
Reflection and audience & $13(46 \%)$ \\
Marketing & $18(64 \%)$ \\
Other learning: Digital literacy & $3(11 \%)$ \\
No use & $4(14 \%)$ \\
\hline \hline
\end{tabular}

$N=28$

Note. Each participant's response was read for any or all of these themes. As a result, counts add up to more than 28 , and percent adds up to more than $100 \%$.

\section{Overall reflection}

When asked, "Did your work to create your portfolio impact your thinking about coaching? Either yourself as a coach or the field of coaching in general," Participant \#4 said this:

I think it was much more like a space to put some ideas together and to reflect and define my identity as a coach. It's much more like a summary of all ideas I have gained through all the other courses and with the other assignments. We read a little of authors, theory ... and we practiced a lot, so this was the opportunity to put them all together and share them.... We had done a lot of reflection before, so this was more an opportunity to put all those things together. 
This participant recognized that reflection was inherent in many courses in the certificate program but suggested that the digital portfolio activities in particular helped her to synthesize the material across courses, "to put all those things together." Participant \#25 took the idea of synthesizing across courses further and developed her unique point of view:

One thing that I really remember doing is looking at all my notes on the class lectures and articles and book chapters that we had read... When I pulled all the pieces out, then I looked through it and figured out what was a consistent thread throughout and how to articulate those in my portfolio.... There's so many approaches and theories and lenses through which to view coaching that we learned about... The portfolio was an opportunity for me to be like, now, what's my approach? What does this say for me? I really felt a -- not a pressure, but I felt a responsibility to represent my own take on coaching and not just regurgitate what we had learned.

Similarly, when asked how the digital portfolio shaped her learning, Participant \#23 responded, "I mean, I keep coming back to the way that it just forced me to develop a point of view as a coach."

Similar to many others, Participant \#17 identified synthesis as a key influence of the digital portfolio assignments on her thinking and learning about coaching, but she added her perception of the influence of writing for a particular audience. Her response to the question regarding impact of her portfolio work on her thinking about coaching:

I think the fact that I needed to cull from different areas and synthesize that and then at the end of the day, get that out for somebody else to consume and, in a sense, to evaluate or judge. And I think that makes you more critical of what you're going to be putting on the page. And I think in a different way than just writing a paper and turning it in.

The benefits of this digital portfolio setting for reflection also extended beyond reflective thinking to reflection regarding her practice:

I think there's a different type of self-imposed pressure or expectation when you're writing something that's going to be viewed by other people when you're describing yourself. For me, it forced me to think a little bit more deeply about not so much which is the model I really agree with, but which of those could I see myself realistically using.

It was not unusual for participants to report benefits of reflection in the portfolio that extended beyond the classroom. Participant \#35 experienced a 
career-altering result of the digital portfolio assignments, where thinking through the portfolio assignments helped her gain clarity on her career:

I will say it while I'm talking about the fact that I don't think that the tool itself [the Digital Portfolio] had a huge impact, I actually do think the process of thinking about creating a digital portfolio contributed to my decision to actually shift my career focus. It made me realize that - and I actually didn't go into the OLCC Program intending to leave my job or to launch a career in coaching; but that is, in fact, now what I'm doing.

\section{Reflection and identity}

As stated earlier, it was not unusual for participants to report benefits of reflection in the portfolio that extended beyond the classroom. Participant \#25 offered this example of how her learning transferred from her professional identity to her personal identity. How the digital portfolio assignments shaped her learning, "Frankly, once I started working on them, I was like this is my philosophy in life not just in coaching. "4 This view of how the portfolio experience brought unity between a sense of self in coaching and a sense of self as a whole was somewhat extreme.

More commonly, alumni reported developing a response to the identity challenges of discovering who they are as a coach as they developed their own, authentic point of view in the portfolio. Participant \#20, for example, reported discovering her niche as a coach:

I pulled in two different pages; one of me as an individual leadership coach and the one as an organizational leadership coach. So it helped me make that distinction.... I've always seen myself as more of an OD consultant, but through the digital portfolio process, I kind of now have reframed it into [being] more of an organizational learning coach, and I like that terminology better. For me, there is a difference. So I feel like there was a small reframe, but a powerful one for me and that was only through the process of the portfolio. I found that language when I was doing my portfolio.

\footnotetext{
${ }^{4}$ Participant \#25's coaching philosophy in her digital portfolio included elaborations on these coaching principles: People are whole and unique and deserving of empathy; awareness and insight precede change; habitual thoughts shape reality; and we don't have to stay stuck - we have choice in how we respond to life.
} 


\section{Reflection and audience}

Returning to Participant \#17, this former student proposed that publishing these assignments on-line for an audience pushed her to think and synthesize in ways that were different than her experience with the reflective assignments that were confined to one particular course. Others used reflection to better understand their audience. Participant \#7, for example,

So it very much helped me get clarity around the populations I wanted to access and then how to message to them. And it prompted me to do a lot of research on, like, how do other coaches talk about what they do and be clear on, you know, how do I describe coaching and what's important in that? That's a long way of saying, yes, it did influence my thinking.

\section{Marketing}

Participant \#48 offered a combination of reflection, identity development and professional branding:

I don't think that I would have the perspective I have as a coach if I had not done that portfolio. Hands down. It was this question of... I had to ask myself the question of, at the core, when I think of who I am as a coach, 'What is the purpose of coaching?' and that's where I got to this like 'unlocking potential'. That right there -- that brand question and that reflection question mattered 100 percent... So like the whole process of forcing me to reflect on this, forced me then to actually integrate it because I'm writing this -- integrating it -- into my own approach to coaching.

Not all participants saw this deep connection between the digital portfolio assignments and their learning and development as a coach. Some saw the value of the portfolio assignments as a tool for marketing themselves as a coach, Participant \#34 for example,

Like I said, I'm still using some of the same content, because I'm still evolving my coaching message. For me, it was a -- how do I say it? I think the challenge with the portfolio -- is it a tool or is it a deliverable? I used it as a tool to help me refine my message and get my thought processes clean.

Participant \#46's response illustrates this utility even more plainly:

Only about how to market it. Not about what I actually do as a coach. I mean, that's helpful because you have to come up with a concise story, you have to come up with a tagline, you have to start thinking about things like that. What am I going to put above the fold? What do I want 
people to be able to access, but not see right off the bat. Things like that. (Interviewer: So it's mostly about marketing yourself as a coach?) Yeah.

Similarly, Participants \#4 and \#15 (respectively) give voice to this perspective, "I think I learned the importance of having one of these tools to sell yourself, like as a marketing piece," and "It helped me learn a little bit more about how I would position myself as an external coach. But I'm not an external coach, and I don't plan on being one."

No Use

As intimated in that last quote, not all students experienced the digital portfolio assignments positively. In fact, four of the participants expressed they did not see where the digital portfolio provided any value at all. When asked if their work to create their digital portfolio had any impact on their thinking about coaching, Participant \#45, for example, said simply, "No." When probed for why not, she responded that it was not a good use of her precious learning time:

That was really not my intent. I didn't come through the program to be a coach. It was more to acquire coaching skills... The [digital portfolio] website was an afterthought for that.... Like most MSLOC students, I have a work life. I have a family life. I have a school life and if anything, it wasn't the best use of my school life time. So it came at the expense of optional readings or whatever it was. So that time came out of my school time that I could have been using to do something else that would have greater value to me moving forward.

Participant \#15 also expressed this sentiment,

I mean, yes and no. I have to be honest, I got more out of conversations with my peers and other people in the cohort about coaching styles and in my coaching circles and coaching groups. I learned more about myself as a coach in those and actually as a coach than I did in creating a portfolio.... It just felt - it felt really forced to me. So I don't know if I took it as seriously as some other people.

And \#36, "Well, for me it just seemed like more of an assignment and it was something I had to do."

\section{Other learning: Digital literacy}

Only three participants spoke directly about the digital aspects of their learning. When answering the question of how the digital portfolio influenced 
learning, Participant \#4 indicated an ordering to her learning, "I learned digital skills first." Participant \#15 responded similarly to that question by indicating that she learned to use a particular digital tool, WordPress. Finally, Participant \#38 indicated gaining a new level of comfort and understanding using the WordPress tool that would result in an increased independence in how they present themselves online.

\section{Implications for coach education programs}

For most students in this study, creating a digital portfolio provided opportunities to extend their learning and development as coaches beyond the achievement of individual course learning objectives. They used the digital portfolio assignments to synthesize coaching experiences, key concepts, and coaching models across courses to develop their unique, authentic identity and point of view. Coaches early in the process of establishing their independent practices also found value in creating content they could use for marketing purposes. One implication of this study is that it is critical to clearly state the program objectives for using digital portfolios and to revisit those objectives with students on multiple occasions. In coach education programs that develop both internal and external coaches, the learning value of portfolios, aside from their marketing potential, is an important point to reinforce. The obvious benefit of creating artifacts for public showcase can sometimes overshadow the benefits of reflective practice, as was seen in some of the student responses. Some students will need supplemental assistance to make connections between their portfolio artifacts and the reflective practice we see as essential to becoming an effective and experienced coach. Adopting the reflective practitioner framework in coach education, through scaffolding reflective practice via digital portfolio assignments, is one way to help students grasp the importance of reflective practice in the ongoing journey of coach development.

A second implication is that the students' process of articulating and refining a coaching perspective for external audiences (potential clients, colleagues, or the public) should not be underestimated - both in terms of its impact on the depth of learning and the support required from instructors. Several participants acknowledged how having an external audience changed the way they processed the program material. One participant described it as a self-imposed pressure, "that makes you more critical of what you're going to be putting on the page... and I think in a different way than just writing a paper and turning it in." Another student put it this way, "I really felt a-not a pressure, but I felt a responsibility to represent my own take on coaching and not just regurgitate what we had learned." Creating portfolios can require 
students to synthesize their coaching experiences and course content in ways that help them find their authentic voices about the field of coaching. Several students in this study appear to have achieved deeper learning as a result. Developing a solid internal foundation for coaching, based on a self-realized coaching philosophy, then allows for an authentic expression of knowledge (Bachkirova, 2016; Baxter Magolda, 2009).

Third, the time and effort required for reflective practice should be factored into curriculum design. Students often were challenged by the time commitment and iterative nature of the process, which at times was frustrating to them - particularly early on in the process when it was less clear to them the value of going through this reflective process. Creating an orientation or introductory workshop for building portfolios can help set the stage, but to reiterate our earlier point, program administrators should revisit portfolio objectives regularly to encourage students and help them make connections. Consistent, repetitive messaging and framing is very important.

Furthermore, the instructional timeline within the program may need to shift to allow students more time for reflective thought, feedback, and iteration. Although many assignments and activities compete for valuable and limited space within each course design, peer feedback often was energizing for students and a catalyst for reflection. Orland-Barek (2005), for example, found that a collaborative process and a space for public reflection during portfolio construction resulted in higher levels of reflective thinking, when supported by "an infrastructure of engagement, mutuality, and continuity" (p. 40). Feedback also can help students overcome barriers, such as balancing the various purposes of the portfolio. Though requiring peer feedback adds another element to the design, it provides students more opportunities to gain awareness, challenge their assumptions, and test how well they are articulating their thinking. Establishing a rubric can help set expectations and provide guidelines for peer feedback.

Finally, working with technology can be a challenge for some. Dedicated technical support and resources for students who need additional help are necessary for effective digital portfolio implementation. The key is keeping the technology from discouraging students or interfering with the reflective process. An important instructional design step is selecting a digital portfolio platform that aligns with the vision students may have for a final product. Some platforms are more oriented toward sharing images, while others are structured similar to websites. Because some coaches may want to use the digital portfolio beyond the educational program, it is beneficial to provide templates and 
platforms that allow them to easily make their work available for public viewing in the format they are most likely to use professionally. Students also will be more motivated to learn the technology if they see its applicability to other aspects of their professional work.

\section{Conclusion}

Reflection is a staple of coaching. It is surprising to us that reflective practice is not equally prominent and widespread in the education of coaches. The skill of facilitating client reflection is a competency all coaches should master, so it seems a natural extension for coaches to be skillful reflective practitioners as well. However, achieving this marker of coaching excellence requires disciplined practice in connection with others. This article explained how digital portfolios can be used to develop reflective practice, and we shared results of a summative design research study that examines student experiences with portfolios. Our findings suggest that using digital portfolios in coach education can promote deep learning. Creating portfolios with an external audience in mind provides the benefits of synthesizing program content, fostering professional identity development, and, for some, crafting artifacts that offer a showcase of expertise for potential clients. Digital portfolio construction requires the same ingredients as reflective practice - awareness, inquiry, discovery, and meaning making. With proper design and scaffolding, portfolios too may become a potent feature of coach education.

\section{References}

21 st Century Learning Reference Group. (2014). Future-focused learning in connected communities (pp. 1-37). New Zealand. Retrieved from https://education.govt.nz/assets/Documents/Ministry/Initiatives/FutureF ocusedLearning30May2014.pdf

Abrami, P., \& Barrett, H. (2005). Directions for research and development on electronic portfolios. Canadian Journal of Learning and Technology / La Revue Canadienne de l'apprentissage et de La Technologie, 31(3). Retrieved from https://www.cjlt.ca/index.php/cjlt/article/view/26487

Anderson, L., \& Wladawsky-Berger, I. (2016, March 24). The 4 things it takes to succeed in the digital economy. Retrieved May 30, 2017, from https://hbr.org/2016/03/the-4-things-it-takes-to-succeed-in-the-digitaleconomy

Arquero, J. L., \& Romero-Frías, E. (2013). Using social network sites in higher education: An experience in business studies. Innovations in Education and Teaching International, 50(3), 238-249. 
Bachkirova, T. (2016). The self of the coach: Conceptualization, issues, and opportunities for practitioner development. Consulting Psychology Journal: Practice and Research, 68(2), 143-156.

https://doi.org/10.1037/cpb0000055https://doi.org/10.1080/14703297.20 12.760772

Baeten, M., Kyndt, E., Struyven, K., \& Dochy, F. (2010). Using student-centred learning environments to stimulate deep approaches to learning: Factors encouraging or discouraging their effectiveness. Educational Research Review, 5(3), 243-260. https://doi.org/16/j.edurev.2010.06.001

Barab, S., \& Duffy, T. (2012). From practice fields to communities of practice. In D. Jonassen \& S. Land (Eds.), Theoretical Foundations of Learning Environments (2nd ed., pp. 31-65). New York, NY: Routledge.

Barrett, H. C., \& Wilkerson, J. (2004). Competing Paradigms in Portfolio Approaches. Retrieved January 25, 2017, from http://electronicportfolios.org/systems/paradigms.html

Barrett, H. C. (2005). Researching electronic portfolios and learner engagement. Ministry of Education and Human Resource Development. Retrieved from http://ww.w.electronicportfolios.org/reflect/whitepaper.pdf

Barrett, H. C. (2007). Researching electronic portfolios and learner engagement: The REFLECT initiative. Journal of Adolescent \& Adult Literacy, 50(6), 436-449. https://doi.org/10.1598/JAAL.50.6.2

Baxter Magolda, M. B. (2009). Authoring your life: Developing an internal voice to navigate life's challenges (1st ed..). Sterling, Va.: Stylus Pub.

Beckers, J., Dolmans, D., \& van Merrienboer, J. (2016). e-Portfolios enhancing students' self-directed learning: A systematic review of influencing factors. Australasian Journal of Educational Technology, 32(2), 32-46.

Bransford, J. D., Brown, A. L., \& Cocking, R. R. (1999). How people learn: Brain, mind, experience, and school. Washington, US: National Academies Press. Retrieved from http://site.ebrary.com/lib/northwestern/docDetail.action?docID=100410 47

Burksaitiene, N., Tereseviciene, M., \& Kaminskiene, L. (2011). Portfolio use for documentation of personal and professional growth gained outside academia. Baltic Journal of Management; Bradford, 6(2), 245-262. http://dx.doi.org.turing.library.northwestern.edu/10.1108/174652611111 31839

Butler, P. (2006). Review of the literature on portfolios and eportfolios. Retrieved from https://akoaotearoa.ac.nz/download/ng/file/group996/n2620-eportfolio-research-report.pdf 
Cavanagh, M. (2006). Coaching from a systemic perspective: A complex adaptive conversation. In D. R. Stober \& A. M. Grant (Eds.), Evidence Based Coaching Handbook: Putting Best Practices to Work for Your Clients (pp. 313-354). Hoboken, NJ: John Wiley \& Sons Inc.

Cavanagh, M., \& Spence, E. (2013). Mindfulness in coaching: Philosophy, psychology, or just a useful skill? In J. Passmore, D. B. Peterson, \& T. Freire (Eds.), The Wiley-Blackwell Handbook of the Psychology of Coaching and Mentoring (p. Blackwell Reference Online). Blackwell Publishing. Retrieved from http://www.blackwellreference.com.turing.library.northwestern.edu/sub scriber/tocnode.html?id=g9781119993155_chunk_g97811199931557

Cheng, G., \& Chau, J. (2013). A study of the effects of goal orientation on the reflective ability of electronic portfolio users. The Internet and Higher Education, 16, 51-56. https://doi.org/10.1016/j.iheduc.2012.01.003, info:doi/10.1016/j.iheduc.2012.01.003

Clark, J. E., \& Eynon, B. (2009). E-portfolios at 2.0 - Surveying the field. Peer Review, AAC\&U, 11(1), 18-23.

Cox, E. (2006). An adult learning approach to coaching. In Evidence based coaching handbook: Putting best practices to work for your clients (pp. 193-204). Hoboken, NJ: John Wiley \& Sons, Inc.

Cox, E., Bachkirova, T., \& Clutterbuck, D. (2014). Theoretical traditions and coaching genres: Mapping the territory. Advances in Developing Human Resources, 16(2), 139-160. https://doi.org/10.1177/1523422313520194

Cunliffe, A. L. (2004). On becoming a critically reflexive practitioner. Journal of Management Education, 28(4), 407-426. https://doi.org/10.1177/1052562904264440

Flaherty, J. (2011). Coaching: Evoking Excellence in Others (3rd ed.). New York, NY: Routledge.

Greenhow, C., Robelia, B., \& Hughes, J. E. (2009). Learning, teaching, and scholarship in a digital age: Web 2.0 and classroom research: What path should we take now? Educational Researcher, 38(4), 246-259. https://doi.org/10.3102/0013189X09336671

Hawkins, P. (2009). Coaching Supervision. The Complete Handbook of Coaching, 381.

Hicks, T., Russo, A., Autrey, T., Gardner, R., Kabodian, A., \& Edington, C. (2007). Rethinking the purposes and processes for designing digital portfolios. Journal of Adolescent \& Adult Literacy, 50(6), 450-458.

Hmelo-Silver, C. E., \& Barrows, H. S. (2008). Facilitating collaborative knowledge building. Cognition and Instruction, 26(1), 48-94. 
Hsieh, H. F., \& Shannon, S. E. (2005). Three approaches to qualitative content analysis. Qualitative health research, 15(9), 1277-1288.

Iordanou, I., \& Williams, P. (2017). Developing ethical capabilities of coaches. In T. Bachkirova, G. Spence, \& D. Drake (Eds.), The Sage Handbook of Coaching (pp. 696-712). London: SAGE Publications Ltd.

Jonassen, D. H. (1999). Designing constructivist learning environments. In C. M. Reigeluth (Ed.), Instructional design theories and models: A new paradigm of instructional theory (Vol. 2, pp. 215-239). Mahwah, N.J.: Lawrence Erlbaum Associates.

Kanatouri, S., \& Geibler, H. (2017). Adapting to working with new technologies. In T. Bachkirova, G. Spence, \& D. Drake (Eds.), The Sage Handbook of Coaching (pp. 713-728). London: SAGE Publications Ltd.

Kemp, T. (2008). Coach self-management: The foundation of coaching effectiveness. In D. B. Drake, D. Brennan, \& K. Gortz (Eds.), The Philosophy and Practice of Coaching: Insights and Issues for a New Era (pp. 27-50). San Francisco, CA: Jossey-Bass.

Land, S. M., Hannafin, M. J., \& Oliver, K. (2012). Student-centered learning environments. In D. Jonassen \& S. Land (Eds.), Theoretical Foundations of Learning Environments (2nd ed., pp. 3-25). New York, NY: Routledge.

Mayer, R. E. (2004). Should there be a three-strikes rule against pure discovery learning? American Psychologist, 59(1), 14-19. https://doi.org/10.1037/0003-066X.59.1.14

McLean, P. (2012). The Completely Revised Handbook of Coaching: A Developmental Aproach. San Francisco, CA: John Wiley \& Sons, Inc.

McLoughlin, C., \& Lee, M. J. W. (2010). Personalised and self regulated learning in the Web 2.0 era: International exemplars of innovative pedagogy using social software. Australasian Journal of Educational Technology, 26(1), 28-43.

Orland-Barak, L. (2005). Portfolios as evidence of reflective practice: What remains 'untold.' Educational Research, 47(1), 25-44. https://doi.org/10.1080/0013188042000337541

Rodgers, C. (2002a). Defining reflection: Another look at John Dewey and reflective thinking. Teachers College Record, 104(4), 842.

Rodgers, C. (2002b). Seeing student learning: Teacher change and the role of reflection. Harvard Educational Review, 72(2), 230-253.

Schön, D. A. (1983). The Reflective Practitioner: How Professionals Think in Action. New York, NY: Basic Books. 
Scott, S. G. (2010). Enhancing reflection skills through learning portfolios: An empirical test. Journal of Management Education, 34(3), 430-457. https://doi.org/10.1177/1052562909351144

U.S. Department of Education Office of Educational Technology. (2010). Transforming American education: Learning powered by technology (pp. 1-22). Retrieved from http://www.ed.gov/edblogs/technology/netp2010/

Vandaveer, V. V., Lowman, R. L., Pearlman, K., \& Brannick, J. P. (2016). A practice analysis of coaching psychology: Toward a foundational competency model. Consulting Psychology Journal: Practice and Research, 68(2), 118-142. https://doi.org/10.1037/cpb0000057

Yancey, K. B. (2009). Electronic portfolios a decade into the twenty-first century: What we know, what we need to know. Peer Review, $A A C \& U$, 11(1), 28-32.

\section{Appendix A}

Interview questions included in the current study.

- Q4: Did your work to create your digital portfolio have any impact on your thinking about coaching (both for yourself as a coach and regarding the field of coaching)?

a. If yes, how? Why?

b. If not, why not?

c. Make sure respondent responds to both:

i. regarding yourself as a coach

ii. regarding the field of coaching

- Q5: What was the most challenging part of creating the portfolio?

- Q6: What did you learn? (OR How did it shape or influence your learning?)

- Q7: What does your portfolio say about you as a coach? As an individual?

\section{Acknowledgements}

Many thanks to the alumni who generously donated their time to take part in this study. The authors would also like to express gratitude to Julian 
Humphreys and two anonymous reviewers for their helpful comments concerning an earlier draft of this paper.

\section{Author Contact}

For questions about this paper, please contact Michelle L. Albaugh,

Northwestern University, 2120 Campus Drive, Evanston, IL 60202. Email:

michelle.albaugh@northwestern.edu 